\title{
ALGUMAS REFLEXÕES SOBRE A FORMAÇÃO DE RECURSOS HUMANOS PARA A SAÚDE PÚBLICA
}

\begin{abstract}
Uma coisa é estimar as necessidades de mão de obra de diferentes qualificaçōes; outra, bem diversa, é levar as pessoas a se prepararem e se engajarem em ocupações que são vitais para o crescimento nacional (Harbison).
\end{abstract}

KRaUSz, R. R. Algumas reflexões sobre a formação de recursos humanos para a saúde pública. Rev. Saúde públ., S. Paulo, 11:151-5, 1977.

RESUMo: São analisadas as funções e relações da Universidade com a sociedade, enfatizando o problema da formação de recursos humanos para a área da Saúde Pública. Focalizando a situação brasileira atual, foram discutidos os aspectos que devem ser considerados pelos servicos de saude quanto às suas expectativas com relaçấo à quantidade e qualidade dos recursos humanos preparados pela Universidade.

UNITERMos: Saude puiblica. Recursos humanos.

A história da Saúde Pública reflete os esforços do homem para alcançar um melhor estado de bem estar físico, mental e social.

Segundo Goerke e Stebbins ${ }^{3}$, em qualquer momento de sua história, a Saúde Pública espelha a interação de três fenômenos básicos: a) a severidade e a natureza dos agravos da saúde; b) as teorias relacionadas com as causas dos agravos e as práticas que dizem respeito ao seu controle e tratamento; c) o caráter da ideologia social prevalecente $\mathrm{e}$ as condições existentes.

A história da Saúde Pública demonstra ainda ${ }^{9}$ que tanto a falta de ações que levam à promoção da saúde, como a luta contra as doenças, dependem da ideologia dominante, das pressões sócio-econômicas situacionais, das manifestações dos agravos de saúde e do estado dos conhecimentos científicos disponíveis num momento histórico determinado.

Tal constatação permite afirmar que o pensamento e as ações de saúde pública estão intimamente relacionados com as condições sociais encontradas ou, como afirma Rosen ${ }^{10}$, "as ações de saúde são um aspecto funcional da sociedade".

$\mathrm{Na}$ atualidade a problemática da Saúde Pública tem atraído a atenção das autoridades, em virtude de sua relevância para

* Do Departamento de Prática de Saúde Pública da Faculdade de Saúde Públíca da UsP Av. Dr. Arnaldo, 715 - Sāo Paulo, SP - Brasil. 
KRAUSz, R. R - Algumas reflexões sobre a formação de recursos humanos para a saúde pública. Rev. Saúde públ., S. Paulo, 11:151-5, 1977.

o desenvolvimento sócio-econômico, principalmente, do chamado terceiro mundo.

As Conferências Internacionais e Nacionais têm focalizado insistentemente problemas de poluição (ecossistemas alterados), saúde materno-infantil, nutrição e crescimento populacional, para citar apenas alguns. No Brasil, esta problemática tem sido amplamente debatida, tanto a nível nacional, como regional.

Um dos aspectos que tem impedido o sucesso de programações nestas áreas diz respeito aos recursos humanos disponíveis. A formação de recursos humanos para a área da Saúde Pública envolve questões extremamente complexas. Uma delas, talvez a mais controvertida, trata do relacionamento entre Universidade $\mathrm{e}$ instituições prestadoras de serviços de saúde.

Muitos estudiosos do problema defendem a idéia da adaptação da Universidade, considerando-a como um sistema produtivo cuja função básica é atender às necessidades sociais. Esta posição é defendida pelos "modernizadores interessados na eficiência nacional" " $"$ que vivem dentro de um contexto de ansiedade relacionado com a competência tecnológica.

Outros. em contraposição. defendem a idéia da transformação social, segundo a qual a Universidade deve ser, em primeiro lugar, um instrumento de transformação social, aproximando os indivíduos e permitindo uma distribuição mais justa dos bens sociais. Outros, ainda, negam que deva existir, necessariamente, um vínculo entre atividades da Universidade e - atendimento das necessidades sociais imediatas; consideram a Universidade uma instituição voltada para a pesquisa pura, para o avanço das fronteiras do conhecimento e para o ensino.

Ao nosso ver, nenhuma destas posições é. isoladamente, satisfatória, redundando cada uma delas, de per si, num paulatino empobrecimento da Universidade e. até mesmo, na sua completa alienação das necessidades sociais.
A Universidade, pela sua própria natureza, deve preencher múltiplas funções, a saber:

a) Atender às necessidades presentes e futuras da sociedade na qual está inserida, em termos de busca de novas soluçóes para os problemas existentes. Isto exige que tanto a pesquisa pura como a aplicada sejam desenvolvidas.

b) Formar recursos humanos capazes de utilizar conhecimentos e práticas gerais e especializadas para atender as necessidades que surgem em conseqüência das mudanças sócio-econômicas.

c) Contribuir para o pleno desenvolvimento das potencialidades humanas com vistas à melhoria das condiçōes de vida das populações.

d) Contribuir para o avanço dos conhecimentos, permitindo a compreensão ampla do ser humano e da vida em sociedade.

Estas funções básicas da Universidade não devem, entretanto, ser consideradas de maneira estanque. Pelo contrário, a qualidade da Universidade dependerá de sua capacidade de combinar dinâmica e flexivelmente estas atividades em termos das transformações do meio ambiente, em seu sentido amplo. No caso específico da Saúde Pública, a Universidade tem um papel crucial na formação de recursos humanos, papel este que tem sido objeto de muitas discussões e debates em virtude da importância que estes recursos humanos representam, não apenas nas ações de saúde propriamente ditas, como também na própria definição da política de saúde a ser seguida. Daí decorre a necessidade de rever constantemente os programas de formação de recursos humanos para a Saúde Pública, com o intuito de oferecer um preparo adequado aos papéis que estes irão exercer nos diferentes escalóes institucionais.

Como afirma Grundy, conforme citado pela OMS ", "é evidente que a formação 
KRALSZ, R. R. - Algumas reflexões sobre a formação de recursos humanos para a saúde pública. Rev. Saúde públ., S. Paulo, 11:151-5, 1977.

em Saúde Pública deve estar estreitamente relacionada, em qualquer lugar ou época com as necessidades e demandas da sociedade, com sua estrutura e instituições, com o nivel de seu desenvolvimento $\mathrm{e}$ com sua concepção da política e do ensino". Daí a necessidade de haver um processo de contínuo reajustamento entre o tipo de formação de recursos humanos e a demanda do mercado consumidor destes profissionais, ou seja, uma compatibilização entre sistema formador e sistema consumidor.

No Brasil, no momento histórico atual, o sistema consumidor tem sofrido uma grande expansão, principalmente em virtude das políticas governamentais. O II Plano Nacional de Desenvolvimento ${ }^{s}$ (PND) afirma que "a solução através do crescimento (econômico) apenas, pode demorar muito mais do que a consciência social admite, em termos da necessidade de melhorar rapidamente o nível de bem estar de amplas camadas da população". Referindo-se especificamente às áreas de Saúde Pública e Assistência Médica da Previdência, diz: "Nas áreas de Saúde Pública e Assistência Médica da Previdência, cuidar-se-á da reforma de estruturas, para dar capacidade gerencial a estes setores, a exemplo do que já se vem fazendo na Educação, especialmente, quanto às Universidades. A competência do Estado para organizar a ação social, com vistas à proteção e recuperação da saúde da população, justifica uma estratégia que visa, primordialmente, à clara definição institucional do setor, com base em mecanismos de coordenação que anulem imprecisões ou superposições de âmbito de atuação".

A expansão repentina da demanda criou uma defasagem entre as necessidades atuais e os recursos humanos disponíveis, claramente diagnosticados pelo Departamento de Assuntos Universitários do Ministério de Educação e Cultura ${ }^{1}$ que diz: "O equacionamento do problema de pessoal se apresenta como da maior importância pa- ra o êxito da implementação de programas de saúde, que carecem, para o desenvolvimento de suas açōes, de uma ampla variedade de profissionais de níveis e modalidades diversas. .. A deficiente capacidade de planejamento dos sistemas formadores e de prestação de serviços de saúde nos seus diferentes níveis, tem sido um dos entraves responsáveis por distorções existentes na formação e utilização dos recursos no setor". Tais afirmaçôes indicam a necessidade de rever-se a formação e utilização dos recursos humanos.

O problema, apesar de complexo, não é insolúvel. Qualquer tentativa de solução, entretanto, deveria considerar dois aspectos fundamentais. $O$ primeiro diz respeito ao adequado dimensionamento das necessidades de mão de obra, abordagem esta que "se tem mostrado adequada, particularmente nos casos de profissões consideradas estratégicas, quer do ponto de vista econômico, quer do ponto de vista social" ", como é o caso da saúde pública. Como afirma Harbison", "necessidades de mão de obra" constituem aquelas necessidades claramente evidentes de pessoas com um tipo particular de educação, treinamento e experiência. A pressuposição é que tais pessoas são necessárias, senão indispensáveis, para a realização de um programa de desenvolvimento nacional".

Este dimensionamento deverá ser feito considerando-se as necessidades de mão de obra a curto, a médio e a longo prazo e tomando-se como quadros de referência - crescimento populacional, a qualidade. quantidade e tipos de serviços a serem oferecidos e, por último, os agravos da saúde existentes. As necessidades de mão de obra deverão incluir, ainda, uma detalhada descrição dos perfis dos profissionais necessários.

O segundo aspecto a ser considerado refere-se à capacidade de absorção dos recursos humanos, ou seja, à possibilidade de alocar-se a mão de obra, oferecendo-se condições de trabalho adequadas em ter- 
KRAUSZ, R. R. - Algumas reflexões sobre a formaçāo de recursos humanos para a saúde pública. Rev. Saúde públ., S. Paulo, 11:151-5, 1977.

mos de atividades e recompensas. A capacidade de absorção dos recursos humanos na área da Saúde Pública, no Brasil, dependerá diretamente das instituições públicas que compōem o sistema saúde, cujo processo de expansão oferece uma perspectiva de absorção a curto prazo bastante promissora, considerando-se o II PND.

É a partir dos aspectos acima mencionados que se desencadeará o equacionamento do problema da formação de recursos humanos para implementar programas de saúde, possibilitando aos centros de formação o preparo de pessoal dentro do limite entre o mínimo essencial das "necessidades de mão de obra" e o "máximo da capacidade de absorção da mesma". Desta forma são evitadas distorções e desequilíbrios na qualidade e quantidade dos profissionais, e respeitada a capacidade de formação destes centros.

O papel da Universidade é de grande importância neste processo. Em primeiro lugar coloca-se a questão de sua capacidade limitada em expandir, em curto prazo, o número de vagas. No caso brasileiro existem apenas dois centros universitários capacitados na área da Saúde Pública. Portanto, qualquer expansão repentina só será possível a custo de sensivel redução qualitativa nos programas de formação de recursos humanos. Em segundo lugar, reduzir a Universidade à função de formadora de recursos humanos apenas. seria restringir sua ação com graves prejuízos futuros. Em terceiro lugar, é preciso lembrar que por mais que a Lniversidade se ajuste às necessidades sociais presentes, dificilmente poderá chegar a formar um profissional sob medida para um setor de mercado de trabalho. O acabamento final deverá ser oferecido segundo as condições específicas das instituições empregadoras, através do treinamento em serviço, operacional e adequado às funções que o profissional irá assumir. Como afirma Harbison " "outro tipo de distorção, em muitos países, é o subdesenvolvi- mento, se não uma evidente negligência, de medidas apropriadas para treinar as pessoas no trabalho".

Focalizando-se o caso da Saúde Pública, observa-se que os centros de formação e, em particular, a Universidade, são incentivados a expandir sua capacidade quantitativa de formação de recursos humanos e, concomitantemente, a especializá-la cada vez mais no afã de atender às necessidades do mercado consumidor. Esta tendência tem prejudicado a própria qualidade dos profissionais, comprometendo desta forma o sucesso dos programas de saúde. Cria-se assim um círculo vicioso, Quanto mais baixo o nível qualitativo dos profissionais, maior será o número necessário para atender os programas de saúde. Desta forma, o déficit de recursos humanos permanecerá. em virtude da menor produtividade ocasionada por preparo inadequado.

Estes aspectos merecem reflexão e devem ser convenientemente ponderados nos ajustamentos que se impõem entre "sistemas formadores e de prestação de serviços de saúde" para evitar que "as distorções existentes na formação e utilização dos recursos", ao invés de serem eliminadas, passem a acentuar-se ainda mais.

Não se deve perder de vista que as funções da Universidade estão centradas não apenas na formação de recursos humanos, mas também no atendimento das necessidades presentes e futuras da sociedade em que está inserida, na contribuição para o avanço dos conhecimentos e do pleno desenvolvimento das potencialidades humanas com vistas à melhoria das condições de vida das populações.

Como diz Harbison 4 "... professores, mestres e administradores de instituições educacionais, em muitos países, podem constituir o grupo maior de inovadores, uma vez que são a semente da qual se desenvolverão as novas gerações de mão de obra". 
KRAUSZ, R. R. - Algumas reflexões sobre a formação de recursos humanos para a saúde pública. Rev. Saúde públ., S. Paulo, 11:151-5, 1977.

Este potencial oferecido pela Universidade deveria ser considerado nos entendimentos entre sistema formador e sistema de prestação de serviços de saúde, ambos engajados no processo de desenvolvimento, processo este que foi definido pelas Na- ções Unidas como sendo "expansão mais transformação; a transformação, por sua vez, é social e cultural tanto quanto econômica, e também, tanto qualitativa como quantitativa" $"$.

KRAUSZ, R. R. [Some reflections on the training of human resources for Public Health.] Rev. Saúde pûbl., S. Paulo, 11:151-5, 1977.

ABSTRACTS: This paper analyzes the relations and functions of the University to society underlining the problem of human resources for Public Health. Emphasising the present Brazilian situation, the aspects to be considered by health services in their expectations on the quantity and quality of human resources trained by the University are pointed out.

UNITERMS: Public Health. Human resources.

\section{REFERENCIAS BIBLIOGRAFICAS}

1. BRASIL. Ministério de Educação e Cultura - Estudo sobre formacão $e$ utilização de recursos humanos na área da saúde. Brasilia, DF, 1976. pp. 11-12.

2. CASTRO, C.M. - A mão de obra universitária: metodologia de planejamento e controvérsias. In: SEMINARIO SOBRE NECESSIDADES, FORMACAO E TREINAMENTO DE PESSOAL DE NIVEL SUPERIOR PARA O SETOR PÜBLICO, Salvador, 1975. Anais. Salvador, 1975. p. 24.

3. GOERKE, L.S. \& STEBBINS, E.L. Mustard's introduction to public health. $\mathbf{5}^{\text {tb }}$ ed. New York, Mac. millan, 1968.

4. HARBISON, F. - A systems analysis approach to human-resource development planning. In: UNESCO. Manpower aspects of educational planning. Bélgica, 1968. p. 60-62.

5. HARBISON, F. - Resources humaines et development. In: UNESCO. Les aspects economiques et sociaux de la planification de l'education. Budapest, 1965 . p. 74 .

6. MINOGUE, K. - The concept of university. Berkeley, Univ. of California Press, 1973. p. 193.

7. ORGANIZACAO MUNDIAL DA SAUDE. Comite de Expertos en Enseñanzas Teóricas y Prácticas de Perfeccionamento en Salud Pública, Ginebra, 1973. Informe. Ginebra, 1973. (Ser. Inf. Teen., 533).

8. PLANO NACIONAL DE DESENVOLVIMENTO (1975.1979), 2.0. Brasília, 1974.

9. ROSEN, G. - A history of public health. New York, M.D. Publications, 1958.

10. ROSEN, G. - Health, history and social sciences. Soc. Sci. Med., y:233$48,1973$.

Recebido para publicacão em 13/07/1976 Aprovado para publicação em 10/09/1976 